\title{
Digital life storybooks for people with dementia living in care homes: an evaluation
}

This article was published in the following Dove Press journal:

Clinical Interventions in Aging

16 September 2016

Number of times this article has been viewed

\section{Ponnusamy Subramaniam ${ }^{\prime}$ Bob Woods ${ }^{2}$}

'Health Psychology Programme, University Kebangsaan Malaysia, Kuala Lumpur, Malaysia; ${ }^{2}$ Dementia Services Development Centre Wales, Bangor University, Bangor, Gwynedd, UK
Correspondence: Bob Woods Dementia Services Development Centre Wales, Bangor University, Ardudwy, Holyhead Road, Bangor, Gwynedd LL57 2PZ, UK

Tel +44 I2483837l9

Email b.woods@bangor.ac.uk
Background and aim: There is increasing interest in using information and communication technology to help older adults with dementia to engage in reminiscence work. Now, the feasibility of such approaches is beginning to be established. The purpose of this study was to establish an evidence-base for the acceptability and efficacy of using multimedia digital life storybooks with people with dementia in care homes, in comparison with conventional life storybooks, taking into account the perspectives of people with dementia, their relatives, and care staff.

Methods: Participatory design was used to create a life story movie based on a previously completed conventional life storybook with six older adults with dementia (four females; mean age 82 years). Relatives were involved in helping the participant to provide additional information and materials for the digital life storybook. In this multiple case study design, both quantitative and qualitative approaches were used. For quantitative purposes, a set of questionnaires that had been completed three times before and after the conventional life storybook was developed were repeated 4 weeks after the life story movie was completed. Semistructured interview questions were designed to collect feedback from participants, relatives, and care staff.

Results: The result indicated that five of the six participants showed additional improvement in measures of quality of life and autobiographical memory. All participants showed improvement or stability in depression scores. Thematic analysis showed that, participants, relatives, and care home staff viewed digital life storybooks as a very useful tool triggering memories and (largely) positive emotions. Participants' case vignettes were presented to document the impact of digital life storybook.

Keywords: care homes, dementia, ICT, life storybook, reminiscence

\section{Introduction}

Using information and communication technology (ICT) to assist people with dementia in everyday life is increasingly popular. ${ }^{1}$ One application with demonstrated feasibility has been to support and facilitate reminiscence work. ${ }^{2}$ Typically, reminiscence work involves using tangible prompts or memory triggers to stimulate discussion and recall of past activities and experiences. These triggers may include photographs, household, and other familiar items from the past, music, and archive sound recordings. ${ }^{3}$ Digital technology offers the potential to present and organize many of these memory triggers in a new way. This application has taken a variety of forms, such as an interactive multimedia storytelling device, ${ }^{4,5}$ multimedia biographies, ${ }^{6,7}$ networked reminiscence systems, ${ }^{8}$ media "memory lane",, YouTube and Internetbased reminiscence work, ${ }^{10}$ personalized reminiscence photograph videos, ${ }^{11}$ networked videophones, ${ }^{12}$ personalized multimedia systems, ${ }^{13}$ and digital life stories using lifelogging entities. ${ }^{14}$ The contents of the reminiscence materials used range from general ${ }^{4}$ to highly personalized. ${ }^{15}$ 
Of the various types of individual reminiscence work that have been practiced, the creation of a life storybook appears to be most effective. ${ }^{3}$ A conventional life storybook includes photographs, pictures, and text, often organized chronologically or in themes, sharing important aspects of the person's biography. Specific events and anecdotes are often included. A digital life storybook would have the potential added benefit of including music (a powerful memory trigger) and other auditory material (including narration), and of using video clips as well as photographs. In a movie format, the digital life storybook would lend itself to being watched with relatively little effort by the person with dementia alone or with others. The aim of this study is to establish the importance of these potential benefits by comparing multimedia digital life storybooks with conventional life storybooks, with people with dementia in care homes, taking into account the perspectives of people with dementia, their relatives, and care staff.

\section{Methods}

This is a mixed method study using a multiple single-case approach ${ }^{16}$ with six participants recruited having completed a previous life storybook project. ${ }^{17}$ Each participant acted as their own control and participants were not blinded to the intervention they received. This project obtained ethical approval from the School of Psychology, Bangor University and the North Wales NHS Research Ethics Committee.

\section{Participants}

Six participants (four female) with mild to moderate dementia living in care homes were recruited for this study (Table 1).

The participants were recruited from the 23 participants in a recently completed randomized controlled trial where two approaches for developing a conventional life storybook were compared. ${ }^{17}$ In the randomized controlled trial, the book was either prepared with the full participation of the person with dementia, through a life review process, or prepared with a relative independently of the person with dementia, and presented to them as a "gift". Assessments were carried out at baseline, 12 weeks later (timed to fit with the end of the life review process for those in this condition), and at 18 weeks. Participants for the current study were selected on the basis that they had given positive feedback on their book, with equal numbers having produced a book through the life review process and having received it as a gift. The average length of their conventional life storybooks was 49 pages (range: 33-65). In addition, each participant had to have their own television in their room and be able to operate it. Written informed consent was obtained from all participants and from one of their relatives. Five participants were rated on the Clinical Dementia Rating $(\mathrm{CDR})^{18}$ with a score of 1 (mild dementia) and one participant had a CDR score of 2 (moderate dementia). The mean age of the participants was 82.2 years (range: $73-89$ ).

\section{Digital life storybook development}

Participatory design was used, with the participant actively involved in the decision-making process, designing and creating, and directing their own life story movie ${ }^{19}$ with the researcher acting as coeditor. A plan and design with timeline were discussed at the outset, and the "Windows Movie Maker" program was used to create a dynamic presentation. Participants' conventional life storybooks had been developed through a structured process. ${ }^{17}$ The digital life storybooks, like the original life storybook, followed a chronological order from childhood until the current time, divided into six segments, eg, childhood, teenage life, career, mid-life, etc, based on the photographs and other visual materials included in the conventional book, augmented with background music, participants' favorite songs, and narration of the story. The participant together with their relative

Table I Participants' demographic information and details of conventional LSB

\begin{tabular}{|c|c|c|c|c|c|c|}
\hline Participants $^{\mathrm{a}}$ & Sex & $\begin{array}{l}\text { Age } \\
\text { (years) }\end{array}$ & CDR & $\begin{array}{l}\text { Previous } \\
\text { group }\end{array}$ & $\begin{array}{l}\text { Length of } \\
\text { LSB (pages) }\end{array}$ & Brief feedback when LSB presented to them \\
\hline John & M & 81 & $\mathrm{I}$ & Life review & 33 & Very nice $[\ldots]$ I can't believe this is for free \\
\hline Sam & M & 74 & I & Gift & 51 & $\begin{array}{l}\text { I can't believe this, my mother will be proud of me } \\
\text { I feel like I'm being appreciated }\end{array}$ \\
\hline Nia & $\mathrm{F}$ & 89 & 2 & Gift & 49 & I feel like I'm famous. I feel very excited \\
\hline Betty & $\mathrm{F}$ & 90 & I & Gift & 40 & This is great. Book about me! Looks like useful book to me \\
\hline Mary & $\mathrm{F}$ & 73 & I & Life review & 54 & One of the best things happened to me after so long \\
\hline Ann & $\mathrm{F}$ & 86 & I & Life review & 65 & $\begin{array}{l}\text { Excellent! Thank you very much }[\ldots] \text { may be this is what } \\
\text { I needed }\end{array}$ \\
\hline
\end{tabular}

Note: ${ }^{a}$ Names are pseudonyms.

Abbreviations: LSB, life storybook; CDR, Clinical Dementia Rating; M, male; F, female. 
and researcher worked together in gathering these additional elements, eg, selecting and sourcing the participant's favorite music, songs, video clips, or footage. Participants' favorite songs and music were used in the soundtrack, matched with appropriate pictures where possible, eg, favorite dance music with a photograph of the participant dancing with his wife. Video clips were also included, eg, a participant's favorite ballet dance clips or favorite football team's highlights clip with songs. The words used by participants during the life review process were also included as quotations.

Based on the input from the participant and his or her relative(s), in the following weeks, the researcher developed a first draft of the movie without any narration. The initial screening took place in the participant's room with their relative(s) for their feedback. The feedback was intended to check the speed of the movie including subtitles and other words, the content, according to timeline, matched music and songs. The participant and relative were able to ask for any alterations and changes in the movie at this point. Once the drafted movie had been altered and adjusted according to the participant's wishes, the narration was recorded, using a voice recorder. The researcher incorporated the voice into the movie by best matching with the pictures and timelines. For those participants lacking in personal materials to support their life story movie chronologically, voice narration and pictures and video-clips from online resources were used.

Narration was provided by participants and relatives. The spoken word was reinforced by the text appearing on the screen or scrolling across the screen, in a clear font, allowing the person sufficient time to read the words if they wished to do so. Three participants decided to record their own narration for their movie (Table 2). One participant recorded his voice together with his nephew. For the remaining two participants, the narrator was a relative.

Once the participant was entirely satisfied with their movie, the movie was burnt onto DVD disks. Three copies were made, one for the participant, one for their family members, and one for the staff of the care home. The DVD cover was printed with a photograph of the participant and titled "Life Story Movie of (participant's name)". The digital life storybook was played on the television in the participant's room with assistance from care staff and relatives. Participants were provided with a DVD player if necessary. The researcher watched the final version of the movie together with the participant at least twice.

The length of movies ranged from 12 minutes to 27 minutes, with an average length of 18 minutes. Three movies were set up to loop and play continuously. On average three sessions were required to test the prototype movie with the participant and their relative before the movie was finalized. The movies took on average 8.3 weeks ( $7-10$ weeks) to produce.

\section{Measures}

After the participant had access to the completed digital life storybook for 4 weeks, a number of questionnaires used in the initial life storybook project were repeated. Follow-up assessments in the initial trial had been completed by an assessor blind to the intervention received by the participant; in this open study, the researcher completed the assessments with the participant. The researcher also sought feedback from the participant, their relatives, and care home staff about the digital life storybook, including the frequency of its use

Table 2 Production descriptions

\begin{tabular}{|c|c|c|c|c|c|c|c|c|}
\hline Participants $^{\mathrm{a}}$ & $\begin{array}{l}\text { Family } \\
\text { member } \\
\text { involved }\end{array}$ & $\begin{array}{l}\text { Voice for } \\
\text { narration }\end{array}$ & $\begin{array}{l}\text { Prototype screened } \\
\text { for feedback }\end{array}$ & $\begin{array}{l}\text { Number of } \\
\text { weeks to } \\
\text { produce }^{\text {b }}\end{array}$ & $\begin{array}{l}\text { Length } \\
\text { (minutes) }\end{array}$ & $\begin{array}{l}\text { Segments }^{c} \\
\text { (chronological) }\end{array}$ & Loop & Multimedia effects \\
\hline John & Nephew & $\begin{array}{l}\text { Both (John } \\
\text { and nephew) }\end{array}$ & $\begin{array}{l}3 \times(I \times \text { with John and } \\
2 \times \text { with John and nephew })\end{array}$ & 10 & 27.02 & Yes & No & $\begin{array}{l}\text { Audio, music, songs, } \\
\text { and words }\end{array}$ \\
\hline Sam & $\begin{array}{l}\text { Brother and } \\
\text { daughter }\end{array}$ & Sam & $\begin{array}{l}4 \times(2 \times \text { with Sam and } \\
2 \times \text { with Sam and brother })\end{array}$ & 9 & 18.06 & Yes & No & $\begin{array}{l}\text { Audio, music, songs, } \\
\text { clips, and words }\end{array}$ \\
\hline $\mathrm{Nia}$ & $\begin{array}{l}\text { Daughter and } \\
\text { granddaughter }\end{array}$ & Granddaughter & $\begin{array}{l}3 \times(2 \times \text { with Nia and } \\
\text { daughter and I } \times \text { with all })\end{array}$ & 9 & 16.47 & Yes & No & $\begin{array}{l}\text { Audio, music, }{ }^{d} \text { songs, }{ }^{d} \\
\text { clips, and words }\end{array}$ \\
\hline Betty & $\begin{array}{l}\text { Son and } \\
\text { daughter in law }\end{array}$ & Betty & $\begin{array}{l}3 \times(2 \times \text { with Betty and } \\
I \times \text { with all })\end{array}$ & 8 & 14.18 & Yes & Yes & $\begin{array}{l}\text { Audio, music, songs, } \\
\text { clips, and words }\end{array}$ \\
\hline Mary & Two sisters & Mary & $\begin{array}{l}3 \times(2 \times \text { with Mary and } \\
I \times \text { Mary and sisters })\end{array}$ & 7 & 12.20 & Yes & Yes & $\begin{array}{l}\text { Audio, music, songs, } \\
\text { clips, and words }\end{array}$ \\
\hline Ann & Daughter & Daughter & $\begin{array}{l}3 \times(I \times \text { with Ann and } \\
2 \times \text { with Ann and daughter })\end{array}$ & 7 & 16.00 & Yes & Yes & $\begin{array}{l}\text { Audio, music, songs, } \\
\text { clips, and words }\end{array}$ \\
\hline
\end{tabular}

Notes: aNames are pseudonyms. ${ }^{b}$ The weeks count from converting life storybook to movie based video, not from beginning of life storybook development in previous project. ' The movie comprises easy to select segments, eg, childhood, schooling, career, married life, etc but can also be played as a continuous movie. ${ }^{\mathrm{d} A l l}$ the music and songs are in Welsh, eg, Welsh national anthem, etc. 
and perceived enjoyment (see Supplementary materials for questions used).

\section{Quantitative measures}

The $\mathrm{CDR}^{18}$ was used as a screening tool to determine the severity of dementia. It is a clinician-rated dementia staging system with five levels from no dementia to severe dementia. Information for the CDR rating was obtained from the participant's medical record, an interview with the participant, relatives and care staff, and by observation.

The following measures were used to monitor changes over time, in comparison with the individual participant's scores during the earlier study.

1. The quality of life-Alzheimer's disease scale ${ }^{20}$ (QOL-AD) is a 13-item questionnaire used here in an interview with the participant to provide an indication of self-reported quality of life. To facilitate its use with cognitively impaired individuals, the QOL-AD uses simple and straightforward language. Higher scores indicate higher quality of life.

2. The autobiographical memory interview ${ }^{21}$ (AMI) consists of two subscales, the personal semantic schedule (PSS) and the autobiographical incident schedule (AIS), seeking, respectively, factual information and memory for events across the person's life. The AMI extended version $^{22}$ (AMI-E) was used as it has additional sections relating to the middle years of the person's life.

3. The geriatric depression scale (Residential) ${ }^{23}$ (GDS-12R) is a brief, 12-item easy-to-administer (yes/no) depression scale that is relevant to residential and nursing home populations.

4. The quality of the caregiving relationship questionnaire ${ }^{24}$ (QCPR) was used to measure the quality of caregiving relationship between the participant and their relative. It has 14 items in total with two subscales, warmth and absence of conflict, and can be completed by both the person with dementia and the relative, providing two perspectives on the relationship. Higher scores indicate a more positive relationship.

\section{Qualitative measures}

In order to collect more in-depth information regarding the perceived value of the digital life storybook, a set of openended questions was developed. The same questions (see Supplementary materials for questions used) were asked with the participant, the relative, the relative as a proxy (answering from the perspective of the person with dementia as they perceived it), staff, and staff as a proxy. The questions were asked in verbal interviews with the participants and with some of their relatives. The staff and some of the relatives chose to provide written responses to the questions. The questions covered feelings and thoughts about the movie, the benefits of the movie, repeat watching of the movie, anything they wanted to change and their preference between the conventional life storybook and the digital life storybook movie. The qualitative data were analyzed using thematic analysis, which involves "identifying, analyzing, and reporting patterns (themes) within data". ${ }^{25}$ The responses from the semistructured interviews were transcribed, and the coded data read and re-read and grouped according to emerging themes and reviewed. Each theme was defined, and the themes were named. This process was checked by another researcher.

\section{Results}

\section{Acceptability and utility of the digital life storybook}

All the six participants successfully engaged in and completed their participation in the project. They all reported enjoying taking part in the project (Supplementary materials, Table S1). None wished to make any changes to their current life story movie. Four participants needed a little assistance from relatives and care staff to operate the DVD player. For the remaining two participants, one could sometimes operate it with a little assistance and sometimes needed someone else to start the movie (mainly due to an antiquated TV set). One participant needed complete assistance due to limited physical movement. However, all participants needed someone to remind them to play the movie. One participant had a reminder note near to the TV asking staff and visitors to turn on the movie - this participant viewed her movie twice as often as the other participants. Most of the participants watched their movie at least three to four times in a week with assistance from a relative, carer, and researcher. When the researcher visited the homes, all the participants' DVD players were found to be connected with the TV set with the DVD disk in the DVD player, in ready to play mode. If given a choice, most of the participants reported preferring to have their life storybook in digital form.

\section{Outcome measures}

Table 3 shows the quantitative results, indicating the change in scores from the end of the initial conventional life storybook project to the point where the person had had the digital life storybook for 4 weeks. Five participants (John, Sam, Betty, Mary, and Ann) had improved scores on the quality of life measure. However, Nia's QOL-AD score decreased by 5 points. 
Table 3 Participant raw scores, mean, and score changes

\begin{tabular}{|c|c|c|c|c|c|}
\hline & Baseline & $\begin{array}{l}\text { After life } \\
\text { review/before } \\
\text { book presented }\end{array}$ & $\begin{array}{l}\text { After having } \\
\text { life storybook }\end{array}$ & $\begin{array}{l}\text { After having } \\
\text { digital LSB }\end{array}$ & $\begin{array}{l}\text { Change following } \\
\text { digital LSB }\end{array}$ \\
\hline \multicolumn{6}{|l|}{ QOL-AD } \\
\hline John & 32 & 37 & 37 & 38 & +1 \\
\hline Sam & 34 & 30 & 31 & 39 & +8 \\
\hline $\mathrm{Nia}$ & 41 & 44 & 45 & 40 & -5 \\
\hline Betty & 38 & 37 & 41 & 43 & +2 \\
\hline Mary & 37 & 43 & 40 & 43 & +3 \\
\hline Ann & 29 & 37 & 37 & 47 & +10 \\
\hline Mean (SD) & $35.17(4.36)$ & $38.0(5.06)$ & $38.50(4.72)$ & $41.67(3.33)$ & +3.17 \\
\hline \multicolumn{6}{|l|}{ GDS-12R } \\
\hline John & 0 & 2 & 2 & 0 & -2 \\
\hline Sam & 3 & 7 & 4 & I & -3 \\
\hline $\mathrm{Nia}$ & I & 0 & 3 & 0 & -3 \\
\hline Betty & 4 & 3 & 2 & 0 & -2 \\
\hline Mary & 3 & 0 & I & I & 0 \\
\hline Ann & 7 & 2 & I & 0 & -1 \\
\hline Mean (SD) & $3.0(2.45)$ & $2.33(2.58)$ & 2.17 (1.17) & $0.33(0.52)$ & -1.84 \\
\hline \multicolumn{6}{|l|}{ AMI (PSS) } \\
\hline John & 27 & 39.5 & 32.5 & 33 & +0.5 \\
\hline Sam & 61.5 & 58 & 61 & 66 & +5 \\
\hline $\mathrm{Nia}$ & 14 & 14 & 15 & 23.5 & +8.5 \\
\hline Betty & 56.5 & 60.5 & 65.5 & 68 & +2.5 \\
\hline Mary & 76.5 & 79 & 71.5 & 94.5 & +23 \\
\hline Ann & $4 I$ & 55 & 55.5 & 69.5 & +14 \\
\hline Mean (SD) & $46.08(23.2)$ & $51.0(22.09)$ & $50.17(21.84)$ & $59.17(26.24)$ & +8.92 \\
\hline \multicolumn{6}{|l|}{ AMI (AIS) } \\
\hline John & I & 3 & I & 4 & +3 \\
\hline Sam & 6 & 6 & 10 & 7 & -3 \\
\hline $\mathrm{Nia}$ & I & 5 & 5 & 2 & -3 \\
\hline Betty & 14 & 14 & 24 & 19 & -5 \\
\hline Mary & 8 & 27 & 10 & 17 & +7 \\
\hline Ann & 8 & 9 & 18 & 10 & -8 \\
\hline Mean (SD) & $6.33(4.93)$ & $10.67(8.87)$ & II.33 (8.43) & $9.83(6.91)$ & -1.5 \\
\hline \multicolumn{6}{|c|}{ QCPR warmth (participants) } \\
\hline John & 35 & 32 & 32 & 39 & +7 \\
\hline Sam & 33 & 32 & 32 & 40 & +8 \\
\hline $\mathrm{Nia}$ & 33 & 31 & 31 & 40 & +9 \\
\hline Betty & 33 & 32 & 33 & 39 & +6 \\
\hline Mary & 32 & 34 & 33 & 36 & +3 \\
\hline Ann & 31 & 32 & 32 & 40 & +8 \\
\hline Mean (SD) & $32.83(1.33)$ & $32.17(0.98)$ & $32.17(0.75)$ & $39.00(1.55)$ & +6.83 \\
\hline \multicolumn{6}{|c|}{ QCPR conflict (participants) } \\
\hline John & 23 & 24 & 24 & 24 & 0 \\
\hline Sam & 24 & 22 & 18 & 29 & $+\mathrm{II}$ \\
\hline $\mathrm{Nia}$ & 23 & 21 & 27 & 18 & -9 \\
\hline Betty & 23 & 22 & 24 & 30 & +6 \\
\hline Mary & 24 & 23 & 24 & 29 & +5 \\
\hline Ann & 24 & 24 & 24 & 30 & +6 \\
\hline Mean (SD) & $23.5(0.55)$ & $22.67(1.21)$ & $23.50(2.95)$ & $26.67(4.80)$ & +3.17 \\
\hline \multicolumn{6}{|c|}{ QCPR warmth (relatives) } \\
\hline John & 31 & 38 & 40 & 40 & 0 \\
\hline Sam & 39 & 35 & 40 & 40 & 0 \\
\hline $\mathrm{Nia}$ & 32 & 32 & 39 & 39 & 0 \\
\hline Betty & 33 & 32 & 37 & 39 & +2 \\
\hline
\end{tabular}


Table 3 (Continued)

\begin{tabular}{|c|c|c|c|c|c|}
\hline & Baseline & $\begin{array}{l}\text { After life } \\
\text { review/before } \\
\text { book presented }\end{array}$ & $\begin{array}{l}\text { After having } \\
\text { life storybook }\end{array}$ & $\begin{array}{l}\text { After having } \\
\text { digital LSB }\end{array}$ & $\begin{array}{l}\text { Change following } \\
\text { digital LSB }\end{array}$ \\
\hline Mary & 39 & 28 & 33 & 36 & +3 \\
\hline Ann & 40 & 39 & 40 & 40 & 0 \\
\hline Mean (SD) & $35.67(4.08)$ & $34.0(4.15)$ & $38.17(2.79)$ & $39.00(1.55)$ & +0.83 \\
\hline \multicolumn{6}{|c|}{ QCPR conflict (relatives) } \\
\hline John & 24 & 24 & 30 & 30 & 0 \\
\hline Sam & 19 & 25 & 30 & 30 & 0 \\
\hline $\mathrm{Nia}$ & 24 & 24 & 23 & 27 & +4 \\
\hline Betty & 25 & 25 & 28 & 28 & 0 \\
\hline Mary & 12 & 18 & 23 & 25 & +2 \\
\hline Ann & 23 & 25 & 28 & 29 & 0 \\
\hline Mean (SD) & $21.17(4.96)$ & $23.5(2.74)$ & $27.00(3.22)$ & $28.17(1.94)$ & +1.17 \\
\hline
\end{tabular}

Note: Names are pseudonyms.

Abbreviations: LSB, life storybook; QOL-AD, quality of life-Alzheimer's disease; GDS-I2R, geriatric depression scale-residential; AMI-E, extended autobiographical memory interview; PSS, personal semantic schedule; AIS, autobiographical incident schedule; QCPR, quality of caregiving relationship.

The average QOL-AD score improved by 3.2 points after having the life story movie, from 38.5 to 41.7 and by 6.5 points from the original baseline. Five participants reported a lower score on the GDS-12R, and the sixth showed no change. The mean level before the digital life storybook was commenced was relatively low (2.2) but had declined by 1.9 points to a mean of 0.3 , indicating an improvement in participants' overall self-reported mood since having their life story movie.

On the AMI-E, all six participants improved their performance on the knowledge aspect of the test. The average improvement was 9 points. However on the "autobiographical incidents" subscale, requiring rich recall of specific events, there was an average decline of 1.5 points, with four participants having a lower score at follow-up. Taking a total score on this test, combining the subscales, five of the six participants showed an improvement, and both subscales showed an improvement from the original baseline.

The quality of relationship between participants and their relative, rated by the person with dementia, showed overall improvement in both subscales. On the warmth subscale, all participants reported improved scores, with a mean improvement of 6.8 points. On the conflict subscale, four participants showed improved scores, with an overall average improvement of 3.2 points. The relatives' rating on quality of relationship also showed overall improvement in both subscales. On the warmth subscale, three relatives (relative of John, Sam, and Ann) scored maximum points at baseline and maintained this score after having the life story movie. Betty and Mary's relatives reported improved quality of relationship, while Nia's relative's score did not change from baseline. The average improvement in the warmth subscale rated by the relative of the person with dementia is 0.8 points. On the conflict subscale, the average improvement was 1.2 points. Three participants' relatives (Sam, Mary, and Ann) reported further improvement, two relatives (John and Sam) maintained the maximum score obtained at baseline and one relative (Betty) showed no changes in the score from baseline. Participants' and relatives' ratings of relationship quality all showed an overall improvement from the original baseline.

\section{Feedback on digital life storybooks from people with dementia, relatives, and staff}

Participants, relatives, and staff welcomed the idea of developing a life story movie and reported a positive experience of taking part in this project. Examples of feedback on the usefulness and benefits of the digital life storybooks are shown in Supplementary materials (Table S2). A number of key themes (Table 4) emerged from the thematic analysis.

First, relatives and people with dementia agreed that the digital life storybook was stimulating and triggered past memories:

The movie brings back my memories. I remember all that in my mind. [Sam]

Bring back memories \& stimulating. [John's relative]

Table 4 Themes emerging from participants, relatives, and staff feedback

\begin{tabular}{ll}
\hline Perspective & Main themes \\
\hline Person with dementia & Stimulating, triggers memories \\
& Enjoyment and feeling good \\
Relatives (proxy) & Stimulating, triggers memories \\
& Enjoyment and feeling good \\
Staff (proxy) & Enjoyment and feeling good \\
Relatives & Encourage conversation \\
Staff & Enjoyment and feeling good \\
\hline
\end{tabular}


A second theme related to the feelings and emotions associated with watching the movie.

Feelings of enjoyment, pleasure, and just "feeling good" were commented upon by people with dementia and relatives. The relatives reported positive emotions in themselves as well as for the person with dementia:

Make me feel good. The movies make me feel happy.

[Betty]

Happy, good mood and she feel famous. [Nia's relative]

Relatives commented on feeling "excited" in watching the movie, perhaps a mix of seeing the person with dementia respond and their own response to the movie:

I felt excited and pleased on mum's behalf [...]. Pleasure in seeing photos of mum's life; obviously it covers some of my life too. [Ann's daughter]

Some memories were associated with mixed emotions.

The movie brings memories/we feel good. Sometimes make us feel sad. [Mary's relative]

Generally, life was seen by the people with dementia positively overall:

I had good life [...] I'm happy about my life. [Betty]

The movie tells my wonderful life. [Sam]

Some staff and relatives commented on how the movie encouraged communication and interaction:

Encouraged Ann to talk about her history. [Care staff]

Help me to spend good half hour with John [...] very pro-

ductive and not like before. [John's relative]

For staff, a major theme related to the information and knowledge they gained about the person with dementia:

Yes, it helped me understand Ann more. Their past/history makes them who they really are, and without information like this, we really don't know them. [Care staff]

Nia's relative felt she now understood her relative's story better and she thought the movie would serve as a living legacy for Nia:

Help me to go back to understand Nia's life better. [Nia's relative]

However, staff also pointed out that the person would often not remember the movie until shown it:

Does not remember seeing it but would like to see it. [Care staff regarding Sam]

\section{Participant vignettes}

Vignettes for four of the participants are presented here; the remaining two are included in the Supplementary materials.

\section{Participant I: John}

John was an 81-year-old widower, diagnosed with dementia over 5 years ago, living in a care home for the last 3 years, His nephew, who had been closely involved in caring for John, agreed to participate with John. He visited the care home regularly.

John was randomly assigned into the life review group in the initial project and he enjoyed taking part in the life review process, which stimulated many pleasant memories, eg, playing golf with his wife, holidays, and dancing with his wife. The life review process also served to remind him of his wife's death, which he found difficult to accept, but comforted himself by the thought they would be re-united when he himself died.

John was very happy with his life storybook and proudly showed it to other residents, staff, and visitors at his care home, explaining about the pictures in his book and talking animatedly about his pictures with his wife.

Approximately 4 months after the final follow-up assessment in the initial project, John was approached again to take part in the digital life storybook project. Both he and his nephew agreed to extend his life storybook to become a life story movie. John's favorite music and songs were recorded and his nephew narrated John's life story. John also recorded a few words about his wife in his own voice. John proposed two main changes at the initial viewing: first the movie was moving too fast for him and he wanted one of the songs matched with photographs of him and his wife dancing. After the movie was revised and finalized, with assistance, John watched his movie at least three to four times a week. The movie triggered many conversations:

It encouraged John to ask questions (while watching the movie) about people he may not have recognized and asking about their whereabouts. [Care staff]

John preferred his story movie compared to his life storybook. He was happy with his movie and said:

Very good! Make me feel good [...] It bring back my memories [...] I remembered I love to play golf [...] I love all the songs, the songs that I and my wife used to dance together $[\ldots]$ Nice $[\ldots]$ very nice.

Interestingly, the care staff thought the life storybook was more suitable for John: 
John has easier access to the book. He can just pick it up when he wants. Operating a DVD would be difficult for him [Care staff]

His nephew's feedback was:

The book is a good idea; the staff will look at it more compared to a DVD. The movie is more useful for a person with dementia and relatives. John's sister thinks the movie project is a great idea and she going to make one for herself.

Both nephew and care staff agree that the movie helps John and themselves:

Makes him (John) happy, brings back memories to him, stimulating and encouraging him to think. I'm not sure about long term effect but for short term it is beneficial. [Nephew]

The movie helped me to spend a good half an hour with John. Very productive and not like last time. [Nephew] I gained more information about John. What music he liked etc. I know about his interests and his family [...] I learned more about John. I think everyone (residents) should have a life story book or movie. [Care staff]

Although the changes in the outcome measures for John are small in this phase of the project (Table 3), his QOL-AD score shows further improvement, remaining at a higher level than the original project baseline, and he scores zero on the depression scale. His autobiographical memory scores are also higher than at the initial baseline. For John, it appears that the major changes in quality of life and autobiographical memory occurred during the life review process, but that the digital life storybook has helped to consolidate these changes.

\section{Participant 2: Nia}

Nia was an 89-year-old widow, who had been resident in the care home for 5 years, receiving regular visits from her daughter in law and other relatives. She had a very active life until developing severe arthritis, which led her to being wheelchair bound. With her daughter in law's cooperation, a life storybook was developed and presented as a gift to her. Quantitatively, the book did not produce any dramatic effect on Nia as shown in Table 3. However, she was very pleased with her book:

Oh dear me! You see [...] this is all about me, I can remember many things now [...] Now I can name all of them (referring to one of her childhood pictures) [...] This book brings back so much of my memories [...] I'm excited [...] thank you so much. [Nia's initial reaction about her book]
After $\sim 5$ weeks to 6 weeks, Nia was approached again to be part of the digital life storybook project. She and her daughter-in-law happily agreed to convert Nia's life storybook into the movie format. Nia was very much interested in Welsh music and managed to list out her favorite music and songs for her movie. Her daughter-in-law helped to collect some of the music and others were obtained from the Internet. The initial screening with background music and songs elicited a positive response, as she sang along with great feeling and with some movement. She explained the meaning of the songs to the researcher (who was not able to understand the Welsh language):

It is a good reminder; she can see her life in chronological order. I'm glad to see her face full of happiness. The music makes her sing together [...] she stopped singing for the past 20 years \& now she is singing again, shaking her hand and leg. [Nia's daughter in law]

Initially Nia agreed to record her own voice for narration. However, after discussion with her family members she decided to record her granddaughter's voice. The movie was screened for a second time with Nia's granddaughter's voice and with other adjustments based on early feedback, eg, rearranging the opening music, the speed of the movie and so on. Nia was very satisfied with her movie but still suggested some further changes (together with her daughter-in-law). The movie was approved at the third screening and burned onto a DVD disk, and a DVD with cover was placed on the DVD player in Nia's room, so it was easy to be noticed by Nia and care staff. When the researcher visited Nia after a few weeks and watched the movie again with her, she said:

I don't know but, I like to watch it again \& again [...] I don't know! I feel happy to watch it. I can see them all again! Just by sitting! Nice memories [...] I feel happy [...] very happy!

During the final feedback, when asked about the book and movie, Nia commented:

I like the book; I always can open \& read. The movie [...] I like too but no one wants to show me! I feel nice if you show to me! Only you show me the movie.

Nia's daughter-in-law also feels that the movie helped her in different ways. For example:

Helps me to go back to understand Nia's life better. The movie helps me to match her story that she used to tell me before. Now, her story makes more sense to me. 
When asked how she felt about taking part in this project, she replied:

I'm glad that I helped Nia to leave her legacy and I did something very good for her. The songs are very good for Nia. The voice from my daughter is brilliant!. The movie helps Nia to ask different questions every time she watches together with me.

Nia's daughter-in-law considered that both the book and the movie were useful:

She likes both; the book makes her to look back (forward and backward). The movie makes her to enjoy more because of voice \& music.

The home manager arranged a session with most of the staff at the care home to watch Nia's movie. They saw having the movie as a wonderful idea and felt every resident should have their own life story movie:

I got to know more about Nia and her family even though I have cared for her ten years and know some family members, still learnt a lot from the movie. [Care staff]

Thought it was very good and well put together. Nice for family to keep. [Care staff]

I will be able to relate more with Nia when she talks about her family. [Care staff]

There is a mixed picture comparing Nia's scores on the outcome measures before and after she had the digital life storybook (Table 3). Whilst her QOL-AD score fell, her (already low) depression score reduced further; her autobiographical knowledge increased, whereas her memory for specific events reduced slightly. Compared with the overall project baseline, the main change was in her improved autobiographical knowledge, and this does appear to be associated specifically with the movie phase of the project.

\section{Participant 3: Betty}

Betty was a 90-year-old widow who moved into residential care 3 years previously due to memory difficulties. She had a great interest in reading and crosswords and spent most of her time engaged in these two activities and less time in conversation with other residents, preferring to be alone. Her son worked closely with the researcher over a period of 3 months to produce Betty's life storybook, which was presented to her as a gift.

Betty was surprised with her book. The book triggered very useful conversations between Betty, her relatives, other residents, and care staff. Her life storybook stimulated her to recall further information about her life story. She gained more points on all primary measures after having the book for 6 weeks. In particular, she improved greatly on AIS scores, reflecting her ability to recount memories of specific incidents in her life with rich content.

Betty and her son were happy to convert the life storybook into a movie. Betty actively recalled all her favorite music and songs with assistance from her son. She decided to also include segments of her favorite radio program and to record her own voice to narrate her movie. Betty made some recommendations and changes (mostly about matching the songs with pictures) to two drafts of the movie before approving the third version.

Betty and her son were as happy with the movie as they were with the book. Betty found the movie stimulating and it triggered many memories in her life. She reports positive feelings whenever she watches her movie:

It reminds me of many things, brings back my memories.

Makes me feel good. The movie makes me feel happy [...]

very triggering. The movie stimulates my memories and makes me look back on my life 'I had a good life' [...] I'm happy about my life.

Although Betty was excited and happy with her conventional life storybook, she reported that the movie was more stimulating and helped her relax more compared with her life storybook:

The movie, because I can see it and reminds me more and makes me very relaxed compared to the book.

Betty's son saw the movie as a Christmas gift for the whole family. Betty's movie was played on Christmas day in a family gathering together with Betty. Her sons and daughter felt that this was a very memorable event because they also shared important segments of Betty's life story:

The movie was quite enjoyable. It made me feel quite good.

It made me think about the past. It helped me to remember things. [Son]

The care home staff were helpful in showing the movie to Betty (usually at night). They thought the movie helped them to understand Betty better and at the same time Betty was proud of her life:

I was very excited. Yes I was able to discuss it and I learned from it. I learned even more about the client. [Care staff] I thought it gave her [Betty] something to be proud of. [Care staff] 
The outcome measures show a mixed picture (Table 3), with a reduction in autobiographical memory for events, but improved quality of life, reduced depression and improved autobiographical knowledge following the exposure to the digital life storybook. All the measures show improvement compared with the initial project baseline assessment and the assessment prior to Betty receiving her conventional life storybook.

\section{Participant 4: Ann}

Ann was an 86-year-old widow diagnosed with vascular dementia, resident in a care home for 3 years. She spent all her day in her room except for meal times, refusing to sit in the lounge and her main interest was reading and watching television. Ann was randomly assigned to the condition where a life storybook was developed through a life review process.

Ann had a huge collection of pictures and other tangible items that covered her entire life. Before the life review process began, the researcher spent hours with Ann's daughter to sort out some of these, according to the phases of Ann's life history. Ann responded well in all the life review sessions. She enjoyed talking about her life story and her pictures really stimulated her memories.

The effect of the life review process on Ann is shown in Table 3. She improved on all measures, although memory for specific events showed relatively little change. Ann scored in the clinical range for depression at baseline assessment but her score was well below the clinical range at the end of the life review sessions.

Ann was very happy and pleased with her book. She spent time reading her own life storybook, sometimes engaging with two or three pages (with pictures) for 20-30 minutes. In Ann's case, her life storybook seemed to acted as a "maintaining tool" for the effects of life review process as shown at 6 weeks after having the book, by which time there was also a more marked improvement in autobiographical memory for specific events.

Ann was very happy to agree to take part in the digital life storybook project. Her daughter provided a collection of Ann's favorite music and songs. Ann chose her favorite background music, songs, and clips for her life story movie. The drafted movie was screened to Ann, and she was pleased with the outcome. Due to breathing difficulties, Ann decided her daughter's voice would be better for the narration. The movie was finalized after three screenings and adjustments. Ann was happy with her movie but seldom watched the movie right through to the end. Instead she used the pause and rewind functions on the DVD player to focus on specific sections.
Apart from being happy and enjoying watching her life story movie, Ann also felt that the movie stimulated her memories:

I think so. I can see back my life stage by stage $[\ldots]$ Wonderful $[\ldots]$ I can see my life again [...] I remember many things that I was never able to remember. The movie tells about me $[\ldots]$ songs and ballet make me happy. Really good! I'm a happy person now. I can sit and watch it!

Although her daughter thinks the opening ballet music in her mother's movie is over dramatic, Ann wanted to retain the movie as it is:

Please don't change anything [...] please! I wish I can have this from a long time ago!

Ann prefers both the movie and the book equally:

Both are the same! I like both. Sometimes I want to read and sometimes I want to watch.

Ann's movie was also positively viewed by Ann's daughter:

I felt excited and pleased on mum's behalf and the family and myself. Mum would really enjoy seeing it. Nostalgic, happy, moved by the ballet section and some of the music. Emotional at times. [Daughter]

The care home staff felt the movie helped them to understand their client better as a person and helped them in the caring process:

A very good idea, which will assist staff in caring for the individual. This movie is very good, with a very high content of information. [Care staff]

Yes, it helped me understand Ann more. Their past/history makes them who they really are, and without information like this, we really don't know them. [Care staff]

I found out things that I never knew about Ann and her life. People who suffer with dementia may go back to a certain point in their life, and knowing more about Ann's past life/history will benefit staff in assisting to Ann's needs. [Care staff]

I was excited to be able to learn more about Ann and her history. We only know about the reason they are admitted to the care home, and their medical history. We have very little or no information about our client. [Care staff]

On the outcome measures (Table 3), Ann's quality of life and factual autobiographical memory reached their highest levels, although memory for specific events appeared to 
decline to around the level immediately after the life review process. She reported no symptoms of depression at all at the final assessment.

\section{Discussion}

It is now well established that a person with dementia may enjoy taking part in many activities and be able to report a good quality of life. ${ }^{26}$ One of the activities highly valued by relatives and care staff is reminiscence work. ${ }^{27} \mathrm{~A}$ tangible outcome of structured individual reminiscence work, life storybooks can be presented in various formats, including making use of ICT. In the current study, we provide further evidence for the feasibility of using ICT-based reminiscence work.

Previous studies have highlighted the positive psychosocial impact of life story work on cognition and emotion for people with dementia. The creation of a life storybook has been viewed positively by participants, relatives and care staff. ${ }^{28-30}$ The life storybook is a tangible aid that appears to be of therapeutic value to a person living with dementia.

In this multiple single case study, the transformation of life storybooks into digital movie life storybooks has been validated. All the six people with dementia approached to take part agreed to do so, and this format has been well received by all participants and their relatives and care staff. All participants valued their own life story movie either more than their life storybook or at least equally. This study has also established that the person with dementia can contribute to the development of his or her life story movie. This participatory design in the production of the movie, with the person with dementia fully directing his or her own life story movie is a strength of this study, and parallels with the development of a life storybook by engaging in a life review process. Disagreements with relatives regarding content and format were rarely encountered, but the emphasis was always on the movie telling the person's own story, as they wished to tell it. It was important for this principle to be stated at the outset, and for the person with dementia to have a clear right of veto (eg, Ann's vignette).

Qualitatively, the life story movie project produced similar effects to the life storybook project, with linked cognitive and emotional effects noted. Not only did participants report the movie helped them in triggering their past memories, but this was accompanied by (largely) positive emotions and "feeling good". Feelings of sadness were expressed, and some tears shed, but these were seen as natural expressions of loss, mitigated by the overall narrative of the life story. Enhanced communication with staff and relatives also may have had an impact on the person's affect, but may also have been assisted by the increased knowledge staff gained regarding the person's life, giving more relevant and interesting topics of conversation. Relatives had positive feelings from watching the movie, which often triggered their own memories, but relatives also felt pleasure in seeing the enjoyment of the person with dementia, in line with other reports of positive outcomes for families. ${ }^{31,32}$ Our qualitative findings thus may be seen as reflecting linked outcomes in relation to cognition (memories triggered/knowledge gained), emotion (positive affect), and enhanced interaction for all parties involved. This perhaps reflects an enhanced "interactional environment" 33 arising from the use of ICT in this way.

The development of the life story movie encouraged person-centered care in that it helped care staff to see their client as a person and to value their experience. The common theme emerging from care staff who took part in the interview and discussion was that they felt that they knew more about the person they care for. Kitwood ${ }^{34}$ emphasizes the importance of understanding the person's life history to provide better care.

In relation to the quantitative measures, the six casestudies show that in all but one instance, the person's highest self-reported quality of life score came after the person had had access to their movie, Similarly, in all but one instance, the person's autobiographical memory for factual knowledge (the PSS score) was at its highest at this point. Depression scores (although generally low) show a similar picture. Memory for specific events and incidents (the AIS score) was only at its highest point at the final assessment for one participant, with this measure peaking after the life review process or after the conventional book had been received for different participants. It is possible to hypothesize that this aspect of autobiographical memory - which comes closest to storytelling - is aided more by the shared experience of a life review process, or of showing a book to another person, whereas the movie may lend itself less to storytelling. The movie moves on at its own preset pace (without the intervention of the pause button), and the moment for recounting an anecdote, a story around a particular event, may be lost. The movie may be better suited to reinforcing personal factual information, with its multiple presentation of the life story, hence the good results on the PSS scale. However, it is important to note that in each case, the final score exceeds the initial score on both subscales of autobiographical memory, despite some months having elapsed between these two time points.

It is of course important not to give too much weight to changes of a few points on these scales, in a small series 
of participants. There are measurement errors on each, and performance on a given day may be influenced by a variety of extraneous factors, including the person's health and mood. For example, the QOL-AD has a Reliable Change Index of 6.8 - reflecting the points change required to be $95 \%$ certain the difference in scores for an individual person with dementia is not due to chance (taking a standard deviation of 5.8 and Cronbachs' alpha of $0.82^{35}$ ). Different assessors carried out the assessments at different points in time, potentially introducing other sources of variability, although all were trained to carry out the assessments, and the researcher (PS) carried out the baseline and final assessments personally. The study was not designed as a group study, and the group changes noted are to be viewed simply as a source of hypotheses for more rigorous, larger scale evaluations. It does seem reasonable, from the six cases presented here, to hypothesize that the effects of a life story movie can reinforce and augment the effects of life review and conventional life storybooks, and that quality of life and autobiographical memory are appropriate outcome measures to consider. The positive outcome for the two cases where the baseline depression score was in the clinical range $(\geq 4)$, also suggests the value of the approach for people with dementia and depression would be worth exploring further. The sample size was too small to consider sex differences, but this would be relevant for larger scale evaluations.

Other limitations include the ceiling effect on ratings of the quality of the relationship on the QCPR. This was apparent for a few people with dementia after having the life story movie. However, the ceiling effect was most obvious on QCPR ratings by relatives whereby some had already achieved maximum scores when the conventional life storybook was presented. Therefore, further effects of life story movie on the relatives' quality of relationship with the person with dementia could not be assessed.

The study is limited also by the lack of a control group and by the lack of blinded postintervention assessments. The study sample were all people who had appreciated having a conventional life storybook; generalization to the whole population of people with dementia, some of whom may not wish to engage in reminiscence, is accordingly uncertain. The study is not able to be informative regarding the effects of producing a digital life storybook without first producing a conventional book. The widespread use of touch screen tablet computers with people with dementia may simplify movie production, and mean that preparing a conventional book becomes less common. This study prepares the ground for a larger scale evaluation of these approaches, with an appropriate control group.
All the participants in the current sample had mild to moderate dementia, and effects on people with more advanced dementia have yet to be established. One suggestion is that having prepared a book or movie earlier in the dementia journey, this will assist with receiving person-centered care and retaining identity ${ }^{36}$ later in the condition, primarily by informing staff, rather than the emphasis being on triggering memories. However, it may continue to be of use as a conversation aid.

In this multiple single-case study, we have established the feasibility of creating digital life storybooks. Life story movies have the advantage over life storybooks in terms of the multimedia effects. The addition of music is particularly striking and was very important to some participants. The relative contribution of the different media components is however difficult to ascertain, and will probably differ from person to person. The success of conventional books suggests that photographs themselves can have therapeutic value. People with dementia were fully involved in directing their movie, recording their own voice or that of their relative in narrating their movie. The songs, clips, and background music stimulate memories from earlier life. All the participants expressed pleasure in viewing their movies. The relatives and staff reported a positive effect of the life story movie on them as well as on the person they cared for. Based on feedback, discussion, and observation, no side or negative effects were reported or observed.

For those people with dementia unable to operate the DVD themselves, staff may need additional prompting to make use of the movie and a conventional life storybook may be a useful supplement, rather than being seen as an alternative. In this study, staff did not find using the digital life storybook burdensome and were convinced of the benefits. However, there are issues of capacity if staff were expected to take on the role undertaken by the researcher here of coproducing the books with the person with dementia. This would require resources of time and of skill in ensuring the involvement of the person with dementia and relatives and ensuring that the person with dementia was able to direct their own story. The widespread implementation of the approach does require further consideration of these issues.

\section{Acknowledgments}

The current study includes material based on sections of the $\mathrm{PhD}$ thesis submitted by Ponnusamy Subramaniam at Bangor University, UK. Ponnusamy Subramaniam's doctoral studies at Bangor University were supported by the Government of Malaysia, and he is currently affiliated with the Health Psychology Unit, Universiti Kebangsaan Malaysia. We 
are grateful to Steven Houlston, Senior Media Technician, School of Psychology, Bangor University, in assisting us in burning and duplicating participants' movies.

\section{Disclosure}

Professor Bob Woods reports grants from "Book of you" nonprofit social enterprise, outside the submitted work. The authors report no other conflicts of interest in this work.

\section{References}

1. SCIE (Social Care Institute for Excellence) [webpage on the Internet]. Using ICT in Activities for People with Dementia: A Short Guide for Social Care Providers. Social Care Institute for Excellence; 2012. Available from: http://www.scie.org.uk/publications/ictfordementia/ index.asp. Accessed April 18, 2016.

2. Subramaniam P, Woods B. Towards the therapeutic use of information and communication technology in reminiscence work for people with dementia: a systematic review. Int J Comput Healthc. 2010;1(2): 106-125.

3. Subramaniam P, Woods B. The impact of individual reminiscence therapy for people with dementia: systematic review. Expert Rev Neurother. 2012;12(5):545-555.

4. Astell AJ, Ellis MP, Bernardi L, et al. Using a touch screen computer to support relationships between people with dementia and caregivers. Interact Comput. 2010;22:267-275.

5. Gowans G, Campbell J, Alm N, Dye R, Astell A, Ellis M. Designing a multimedia conversation aid for reminiscence therapy in dementia care environments. Extended Proceedings of the CHI 2004 Conference on Human Factors in Computing Systems. New York: ACM; 2004: 825-836.

6. Cohene T, Baecker RM, Marziali E, Mindy S. Memories of a life: a designcase study for Alzheimer's disease. In: Lazar J, editor. Universal Usability. Chichester: Wiley; 2006:357-487.

7. Smith KL, Crete-Nishihata M, Damianakis T, Baecker RM, Marziali E. Multimedia biographies: a reminiscence and social stimulus tool for persons with cognitive impairment. J Tech Hum Serv. 2009;27:287-306.

8. Kuwahara N, Abe S, Yasuda K, Kuwabara K. Networked reminiscence therapy for individuals with dementia by using photo and video sharing. ASSETS 06. Proceedings of the 8th International ACM SIGACCESS Conference on Computer and Accessibility. New York: ACM; 2006: $125-132$.

9. Olsen RV, Hutchings BL, Ehrenkrantz E. "Media memory lane" interventions in an Alzheimer's day care center. Am J Alzheimers Dis Other Demen. 2000;15(3):163-175.

10. O'Rourke J, Tobin F, O'Callaghan S, Sowman R, Collins DR. 'YouTube': a useful tool for reminiscence therapy in dementia? Age Ageing. 2011;40(6):742-758.

11. Yasuda K, Kuwabara K, Kuwahara N, Abe S, Tetsutani N. Effectiveness of personalised reminiscence photo videos for individuals with dementia. Neuropsychol Rehabil. 2009;19(4):603-619.

12. Kuwabara K, Tetsutani N, Kuwahara N, et al. Networked interaction therapy: supporting people with mild dementia and their family members with internet. In: 20th International Conference of Alzheimer's Disease International; October 2004. Kyoto, Japan. Abstracts p. 377.

13. Sarne-Fleischmann V, Tractinsky N. Development and evaluation of a personalized multimedia system for reminiscence therapy in Alzheimer's patients. Int J Soc Hum Comput. 2008;1:81-96.

14. Kikhia B, Hallberg J, Bengtsson JE, Savenstedt S, Synnes K. Building digital life stories for memory support. Int J Comput Healthc. 2010; 1(2):161-175.

15. Massimi M, Berry E, Browne G, Smyth G, Watson P, Baecker RM. An exploratory case study of the impact of ambient biographical displays on identity in a patient with Alzheimer's disease. Neuropsychol Rehabil. 2008;18(5/6):742-765.
16. Yin RK. Case Study Research: Design and Methods. 4th ed. Thousand Oaks, CA: Sage; 2009.

17. Subramaniam $P$, Woods B, Whitaker C. Life review and life story books for people with mild to moderate dementia: a randomised controlled trial. Aging Ment Health. 2014;18(3):363-375.

18. Hughes CP, Berg L, Danziger WL, Coben LA, Martin RL. A new clinical scale for the staging of dementia. Br J Psychiatry. 1982;140: $566-572$.

19. Greembaum J, Kyng M. Introduction: Situated Design, Design at Work: Cooperative Design of Computer Systems. Mahwah, NJ: Lawrence Erlbaum Associates; 1991.

20. Logsdon RG, Gibbons LE, McCurry SM, Teri L. Assessing quality of life in older adults with cognitive impairment. Psychosom Med. 2002;64(3):510-519.

21. Kopelman MD, Wilson BA, Baddeley A. The Autobiographical Memory Interview. Suffolk: Thames Valley Test Company; 1990.

22. Woods RT, Bruce E, Edwards RT, et al. Reminiscence groups for people with dementia and their family carers: pragmatic eight-centre randomised trial of joint reminiscence and maintenance versus usual treatment: a protocol. Trials. 2009;10:64.

23. Sutcliffe C, Cordingley L, Burns A, et al. A new version of the geriatric depression scale for nursing and residential home populations: the geriatric depression scale (residential) (GDS-12R). Int Psychogeriatr. 2000;12(2):173-181.

24. Spruytte N, Van-Audenhove C, Lammertyn F, Storms G. The quality of the caregiving relationship in informal care for older adults with dementia and chronic psychiatric patients. Psychol Psychother. 2002;75(pt 3):295-311.

25. Braun V, Clarke V. Using thematic analysis in psychology. Qual Res Psychol. 2006;3:77-101.

26. Woods B. Well-being and dementia - how can it be achieved?. Qual Ageing Older Adult. 2012;13(3):205-211.

27. Gibson F. Reminiscence and Recall: A Guide to Good Practice. 3rd ed. London: Age Concern England; 2006.

28. Haight BK, Gibson F, Michel Y. The Northern Ireland life review/ life storybook project for people with dementia. Alzheimers Dement. 2006;2(1):56-58.

29. Lai CKY, Chi I, Kayser-Jones J. A randomized controlled trial of a specific reminiscence approach to promote the well-being of nursing home residents with dementia. Int Psychogeriatr. 2004;16(1):33-49.

30. Morgan S, Woods RT. Life review with people with dementia in care homes: a preliminary randomized controlled trial. Nonpharmacol Ther Dement. 2010;1:43-60.

31. Damianakis T, Crete-Nishihata M, Smith KL, Baecker RM, Marziali E. The psychosocial impacts of multimedia biographies on persons with cognitive impairments. Gerontologist. 2010;50(1):23-35.

32. Cohene T, Baecker R, Marziali E. Designing interactive life story multimedia for a family affected by Alzheimer's disease: a case study. Poster Presented at: The Conference on Human Factors in Computing Systems, April 2-7, 2005; Portland, OR.

33. Purves B, Savundranayagam MY, Kelson E, Astell A, Phinney A. Fostering resilience in dementia through narratives: contributions of multimedia technologies. In: Resnick B, Gwyther LP, Roberto KA, editors. Resilience in Aging: Concepts, Research \& Outcomes. New York: Springer; 2011:231-243.

34. Kitwood T. Dementia Reconsidered: The Person Comes First. Buckingham: Open University Press; 1997.

35. Thorgrimsen L, Selwood A, Spector A, et al. Whose quality of life is it anyway? The validity and reliability of the quality of life-Alzheimer's disease (QOL-AD) scale. Alzheimer Dis Assoc Disord. 2003;17(4): 201-208.

36. Rubinstein RL. Reminiscence, personal meaning, themes and the 'object relations' of older people. In: Webster JD, Haight BK, editors. Critical Advances in Reminiscence Work: From Theory to Application. New York: Springer; 2002:153-164. 


\section{Publish your work in this journal}

Clinical Interventions in Aging is an international, peer-reviewed journal focusing on evidence-based reports on the value or lack thereof of treatments intended to prevent or delay the onset of maladaptive correlates of aging in human beings. This journal is indexed on PubMed Central, MedLine,

CAS, Scopus and the Elsevier Bibliographic databases. The manuscript management system is completely online and includes a very quick and fair peer-review system, which is all easy to use. Visit http://www.dovepress. com/testimonials.php to read real quotes from published authors. 